\title{
Konsep Design Thinking pada Lembaga Bimbingan Belajar Smartnesia Educa
}

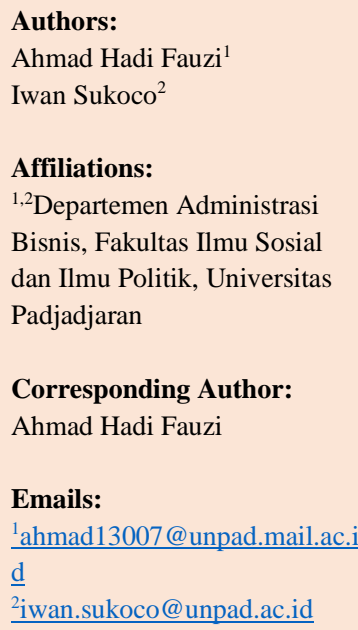

Corresponding Author: Ahmad Hadi Fauzi

Emails:

1ahmad13007@unpad.mail.ac.1

d

2iwan.sukoco@unpad.ac.id

Article History:

Received: March 18, 2019

Revised : April 12, 2019

Accepted: June 12, 2019

How to cite this article: Fauzi, A. H., \& Sukoco, I. (2019). Konsep Design Thinking pada Lembaga Bimbingan Belajar Smartnesia Educa. Organum: Jurnal Saintifik Manajemen dan Akuntansi, 2(1), 37-45. doi: https://doi.org/10.35138/organu $\underline{\text { m.v2i } 1.50}$

\section{Journal Homepage:} ejournal.winayamukti.ac.id/ind ex.php/Organum

\section{Copyright:}

(C) 2019. Published by Organum: Jurnal Saintifik Manajemen dan Akuntansi Faculty of Economics and Business. Winaya Mukti University.
Abstract. Design thinking has become one of the model approaches that can be carried out by a business entity. The design concept approach model is widely chosen because it has several stages and thought lines that are systematic, mutually sustainable, understanable and applicable. Therefore, this study aimed to determine the use of design thinking approach models in business entities, which are the research locus, namely in Smartnesia Educa. This research used a descriptive analysis method using a qualitative approach. The data collected was secondary and primary data in the form of interviews and supporting documents in Smartnesia Educa. The results of this study indicated that Smartnesia Educa had applied the design thinking in its operational business processes to become heterogeneous tutoring and could be accepted by all levels of economic and social markets.

Keywords: Strategy; design thinking; competitive advantage; smartnesia educa.

Abstrak. Design thinking menjadi salah satu model pendekatan yang dapat dilakukan oleh sebuah entitas bisnis. Model pendekatan konsep design thinking banyak dipilih karena memiliki beberapa tahapan dan alur pikir yang sistematis, saling berkesinambungan, dan mudah dipahami dan diterapkan. Oleh karena itu, penelitian ini bertujuan untuk mengetahui penggunaan model pendekatan design thinking pada entitas bisnis yang menjadi lokus penelitian yaitu di Smartnesia Educa. Penelitian ini menggunakan metode analisis deskriptif dengan menggunakan metode pendekatan kualitatif. Data yang dikumpulkan merupakan data sekunder dan primer yaitu berupa hasil wawancara dan dokumen-dokumen pendukung yang ada di Smartnesia Educa. Hasil dari Penelitian ini menunjukkan Smartnesia Educa sudah menerapkan design thinking dalam proses operasional bisnisnya untuk menjadi bimbel yang heterogen dan dapat diterima oleh semua lapisan pasar ekonomi dan sosial.

Kata Kunci: Strategi; design thinking; keunggulan kompetitif; smartnesia educa.

\section{Pendahuluan}

$\mathrm{P}$ ersaingan usaha pada lembaga pendidikan yaitu bimbinga n belajar pada era ini mulai sangat kompetitif. Berbagai konsep dan metode bimbingan belajar yang dirancang oleh masing-masing lembaga bimbingan belajar menjadi keunggulan tersendiri. Lembaga bimbingan belajar Smartnesia Educa dituntut mampu berinovasi dalam mengikuti permintaan pasar, hal tersebut dilakukan agar memiliki keunggulan kompetitif dari para kompetitornya. Smartnesia Educa memerlukan beberapa strategi terdiri dari perancangan bisnis 
serta manajemen pelaksanaan organisasi pada lembaga bimbingan belajar yang memberikan bimbingan belajar.

Sebuah organisasi atau perusahaan dalam pembuatan strategi perancangan bisnisnya agar dapat tetap bertahan di pasar yang kompetitif saat ini, organisasi harus memiliki sebuah keunggulan kompetitif. Indikator keunggulan kompetitif berkelanjutan yang digunakan adalah bernilai, berbeda dengan yang lain, dan tidak mudah digantikan (Suendro, 2010). Bahkan dengan memberikan sebuah nilai lebih atau pembeda yang berupa inovasi di dalamnya. Menurut Ojasalo (2008), inovasi dapat dimulai pada produk/layanan, proses, dan pasar. Melalui inovasi sebuah perusahaan atau organisasi dapat memiliki daya pembeda dengan perusahaan atau organisasi lainnya. Fenomena tersebut juga terjadi pada Smartnesia Educa yang harus memiliki keunggulan kompetitif pada produknya agar dapat diterima oleh pasar.

Salah satu konsep yang digunakan dalam pemecahan masalah yang dihadapi oleh Smartnesia Educa agar dapat bersaing di pasar yaitu dengan menggunakan pendekatan konsep design thinking. Konsep pendekatan design thinking merupakan sebuah konsep pemecahan masalah yang dikembangkan oleh Brown dan Wyatt. Pemecahan masalah ini dinilai efektif karena dapat menghasilkan solusi yang sesuai dengan kebutuhan user (Zaki \& Sukoco, 2018). Di beberapa negara, kaidah ini telah dikembangkan dalam berbagai bidang seperti dunia bisnis, pengembangan produk, sosial, budaya, keputusan politik, kebijakan hingga berbagai strategi jangka pendek dan jangka panjang (Purnomo, 2013). Pada penelitian terdahulu konsep ini dinilai cukup efektif karena dapat menghasilkan solusi efektif atas permasalahan yang sedang dihadapi, seperti penciptaan inovasi dalam produk atau problem solver (Amalina, Wahid, Satriadi, Farhani, \& Setiani, 2017; Saputra, 2018). Tujuan penelitian ini untuk meneliti dan memaparkan hasil penerapan metode design thinking pada perusahaan yang bergerak di bidang jasa pada bimbingan belajar Smartnesia Educa.

\section{Kajian Literatur}

\section{Design Thinking}

Design thinking merupakan sebuah pendekatan dalam membuat sebuah pengalaman yang menyangkut dampak emosional, estetika, serta interaksi yang berorientasi terhadap nilai sosial (Hartson \& Pyla, 2012). Metode ini memiliki beberapa tahapan mulai dari pengumpulan informasi mengenai pengguna, berdasarkan informasi tersebut dibuat mengenai apa yang dibutuhkan pengguna, membuat solusi-solusi kreatif, membangun representasi dari solusisolusi yang ditawarkan, dan menguji hasil representasi yang telah dibangun sehingga mendapatkan feedback.

Terdapat beberapa versi tahapan dalam proses design thinking, namun pada prinsipnya adalah sama yaitu memberikan gambaran melalui tahapan-tahapan bagaimana menciptakan sebuah desain inovatif yang didasari dari permasalahan spesifik kebutuhan manusia, serta menghasilkan solusi yang dapat diaplikasikannya secara umum. (Ambrose \& Harris, 2010) mengadopsi metode design thinking menjadi 7 kerangka berpikir dalam perancangan produk yang sistematis. Tujuh tahapan tersebut adalah exploration, identification, ideation, visualisation, prototyping, evaluation, dan persuation. (Ingle, 2013) membagi proses design thinking menjadi 4 fase kerangka berpikir. Keempat pilar tersebut adalah phase 1 understanding, phase 2 define, phase 3 ideate, phase 4 prototype dan test.

Sedangkan Brown \& Wyatt (2010) menekankan bahwa design thinking merupakan sebuah interaksi yang berorientasi pada manusia (human oriented), yang di dalamnya ada proses berempati, integrative thinking, optimism (sebagai sebuah value), experimentalism 
(yang lahir dari hati), dan collaboration (hubungan yang mendalam) yang semuanya itu digambarkan/dipetakan menjadi 3 pilar penting dari proses berpikir desain. Ketiga bagian tersebut adalah inspiration, ideation, dan implementation.

Inspirasi adalah bagian pertama dalam proses berpikir dalam kaidah design thinking menurut Brown. Di dalam inspirasi ada proses mengumpulkan dan menggali insight, sebagai bagian dari upaya belajar dari orang lain (pelanggan) dan memperhatikan apa yang orang lain lakukan. Termasuk juga berempati dengan ikut merasakan dan mencoba berganti posisi ketika menjadi orang lain. Di dalam inspirasi juga terdapat aktivitas oleh observasi sebagai bagian dari mengenali secara mendalam untuk menangkap polapola atau patterns yang ada dan mencoba memikirkan kemungkinan-kemungkinan yang akan terjadi kemudian. Memetakan bagian-bagian yang sama dari yang dilihat dan dirasa adalah cara paling mudah dalam observasi. Inti dari bagian pertama ini bertujuan untuk menangkap point of view dari permasalahan spesifik yang muncul melalui pengamatan mendalam. Temuan ini akan menjadi bagian dari perencanaan awal sebuah proses desain.

Bagian kedua adalah proses ideation. Tahapan ini diawali dari proses berpikir divergen. Cara berpikir divergen ini adalah dengan membuat berbagai macam alternatif dari ide-ide baru yang tak terbatas. Dari banyaknya pilihan ideide baru tersebut kemudian dilakukan proses penyaringan untuk mendapatkan hasil terbaik dari pilihan-pilihan yang sudah diberikan melalui pikiran yang terbuka untuk bereksperimen dan bertukar pikiran (Brainstorming). Proses berpikir seperti ini disebut sebagai cara berpikir konvergen. Menurut Brown, cara berpikir semacam ini disebut sebagai divergent and convergent thinking yang di dalamnya terdapat proses analisis dan sintesis, mengumpulkan, mengolah, dan menyaring data. Proses analisis dan sintesis disampaikan melalui berbagai cara, bisa melalui media visual, menulis atau mendeskripsikan temuan melalui cerita, mendokumentasikan gambar bahkan sampai dengan mewujudkan ide dengan membuat model atau prototype. Tujuan dari pembuatan protoype ini adalah untuk menemukan kelemahan dan kelebihan dari sebuah ide dan menunjukkan arah perbaikan yang lebih baik.

Tahapan berikutnya adalah proses implementasi. Proses ini adalah mewujudkan ide-ide inovatif dalam bentuk prototype. Di dalam pembuatan model prototype, diperlukan proses iterasi, yaitu evaluasi bersama mentor yang berpengalaman dan dilakukan berulang-ulang sampai menghasilkan bentuk desain yang optimal. Di dalam proses implementasi ini juga ada kegiatan evaluasi dan persuasi terhadap apa yang sudah dibuat serta memutuskan bagaimana keberlangsungan produk tersebut. 
Gambar 1. Tiga pilar yang menjadi dasar design thinking dari Tim Brown.



Sumber : Design Thinking (Tim Brown, 2008)

Berdasarkan Gambar 1, design thinking memberikan kerangka berpikir yang sistematis, di dalam prosesnya tidak hanya searah atau linear namun bersiklus, mengalami proses iterasi (lateral) untuk hasil yang optimal sehingga mampu memberikan stimulus terhadap lahirnya inovasi yang human oriented dan berdampak secara luas.

Tiga pilar penting dalam design thinking dijabarkan menjadi 5 tahapan proses yang saling terkait secara linier dan lateral. Proses linier terjadi pada semua tahapan secara sistematis. Namun, pada tahapan ideasi sampai evaluasi terjadi proses lateral yang berulang (iterasi). Proses iterasi dilakukan sebagai bentuk perbaikan, mencari kekurangan, dan menyempurnakan di tahapan berikutnya. Berikut merupakan gambaran 5 tahapan dalam proses design thinking.

\section{Gambar 2. Proses penjabaran tahapan design thinking}



Sumber: Design Thinking Process Stanford University (Plattner, 2019)

\section{Metode Penelitian}

Penelitian ini menggunakan metode analisis deskriptif dengan menggunakan metode pendekatan kualitatif. Tahapan penelitian kualitatif yaitu, peneliti melakukan observasi dengan melakukan 
pengamatan langsung terhadap subjek penelitian. Setelah itu peneliti melakukan wawancara kepada lima orang yaitu CEO, penggajar, bagian kurikulum dan $\mathrm{R} \& \mathrm{D}$, kesekretariatan, serta public relations dengan 5 tahapan fokus utama wawancara mengenai konsep pendekatan design thinking di Smartnesia Educa meliputi proses Empathize, Define, Ideate, Prototype, dan Test demi memperoleh data yang memadai dan makna yang rasional (Plattner, 2019). Selain itu dilakukan studi dokumentasi sebagai pendukung yaitu dokumen-dokumen yang ada di Smartnesia Educa yang tertulis resmi ataupun tidak resmi. Data yang sudah peneliti kumpulkan kemudian dianalisis dengan metode analisis deskriptif. Metode analisis deskriptif digunakan untuk mendeskripsikan faktafakta yang ada, kemudian disusul dengan analisis untuk memberikan pemahaman dan penjelasan yang secukupnya.

\section{Hasil dan Pembahasan}

Smartnesia Educa merupakan lembaga yang bergerak di bidang jasa bimbingan belajar dengan menggunakan pendekatan konsep design thinking sebagai guideline dalam kegiatan proses bisnisnya. Design thinking tidak hanya menjadi framework dari proses kegiatan operasional, namun juga terhadap proses kegiatan bisnis bersama para konsumen (Ardian \& Werdhaningsih, 2019; Saputra, 2018). Pemilihan konsep pendekatan design thinking tidak didasarkan hanya kepada fleksibilitasnya terhadap multidisiplin namun juga terhadap keefektifan prosesnya dalam memecahkan sebuah masalah-masalah dengan berupa inovasi (Brown \& Wyatt, 2010). Menurut Ackoff, Magidson, \& Addison (2006) Konsep pedekatan design thinking yaitu sebuah proses berfikir tentang perubahan dengan konsep sederhana, namun dapat menyelesaikan masalah-masalah yang dihadapi. Untuk mendapatkan hasil yang terbaik perlu melakukan pengamatan serta membayangkan sebuah ide-ide yang ideal dari sebuah masalah. Pada penelitian terdahulu konsep pendekatan design thinking digunakan untuk membuat ideide baru dalam pengembangan sebuah produk yang sesuai pengguna (Ardian \& Werdhaningsih, 2019; Batmetan et al., 2018; Saputra, 2016). Serta penggunaan design thinking dapat digunakan untuk mencari solusi yang inovatif dari sebuah masalah (Amalina et al., 2017).

Hasil dari observasi lapangan dengan menggunakan studi wawancara kepada CEO Smartnesia Educa. Pengunaan design thinking dalam usaha bimbel dilakukan untuk memecahkan masalah yang ada di dalam usahanya. Smartnesia Educa melakukan design thinking process agar produk yang dihasilkan dapat diterima dan dijangkau oleh lingkungan geografis dan demografis. Proses design thinking yang dilakukan oleh Smartnesia Educa mengikuti lima tahapan yang bersifat literatif dan Flexible, yaitu Empathize, Define, Ideate, Prototype, dan Test (Ardian \& Werdhaningsih, 2019; Batmetan et al., 2018; Saputra, 2018).

Tahapan pertama yaitu empathize yakni menggali lebih dalam dan mencari wawasan atau insight terhadap problematika yang dihadapi oleh Smartnesia Educa. Tahapan empathize adalah sejauh mana mampu memahami dan merasakan permasalahan yang ada. Tahapan ini fokus pada permasalahan dan mengungkapkan yang ada dipikiran adalah yang paling utama serta dapat menempatakan diri sebagai konsumen yang dituju (Ardian \& Werdhaningsih, 2019). Ketika sudah mengetahui user yang akan dituju, hal yang dilakukan oleh Smartnesia Educa yaitu perlu mengetahui pengalaman, emosi, dan situasi dari lingkungan dan target market. Smartnesia Educa mencoba menempatkan diri sebagai pengguna dan bagian dari market, sehingga dapat benar-benar memahami kebutuhan pengguna yang dituju. Hal ini dapat dilakukan dengan melakukan wawancara, observasi kehidupan market, 
dan cara lainnya. Market umum dari Smartnesia Educa merupakan keluarga yang mempunyai anak-anak usia sekolah TK, SD, SMP, serta SMA. Smartnesia Educa membagi user menjadi potential consumer dan potential customer. Hasil penelitian menunjukkan bahwa Smartnesia Educa telah melakukan tahap empathize ini dengan mengunjungi sekolah-sekolah yang berada dalam area target pasar Smartnesia Educa dalam rangka melakukan observasi dan melakukan wawancara terhadap target pasar dari sisi potential consumer, yakni para siswa sekolah untuk melihat pola belajar siswa di sekolah maupun di luar sekolah, ekspektasi siswa terhadap bimbingan belajar, dan posisi bimbingan belajar di benak siswa. Tahap empathize selanjutnya, seperti yang dituturkan oleh CEO Smartnesia Educa, yaitu melakukan observasi dan wawancara kepada potential costumer yaitu orang tua siswa atau wali murid untuk mendapatkan insight dan opini mengenai jasa bimbingan belajar, posisi lembaga bimbingan belajar di benak customer, dan range harga yang ada di pasaran. Tahap empathize ini telah dilakukan oleh Smartnesia Educa sebagai tahap awal pembangunan bisnis.

Tahapan kedua dari design thinking adalah define. Pada proses define ini mampu memberikan lebih banyak gambaran mengenai permasalahan yang terjadi dan hal-hal yang selama ini dianggap biasa, namun ternyata cukup penting untuk diperhatikan dan dicarikan solusinya (Ardian \& Werdhaningsih, 2019). Smartnesia Educa dituntut mengerti kebutuhan market, maka Smartnesia Educa membuat gambaran sebuah ide serta pandangan dari konsumen yang akan menjadi dasar dari jenis layanan belajar yang akan digunakan. Hal ini dapat dilakukan dengan membuat list kebutuhan market dan menggunakan pengetahuan mengenai kondisi yang sedang terjadi. Hasil penelitian menunjukkan tahapan define di
Smartnesia Educa dilakukan dengan beberapa tools seperti analisis SWOT dan strategi SWOT. Data mentah dari tahap empathize diolah untuk analisis mendalam mengenai lingkungan internal dan eksternal, kekuatan, kelemahan, peluang, dan ancaman bisnis Smartnesia Educa serta perencanaan strategis (strategic planning) yang akan dilakukan.

Tahapan ketiga ideate, pada tahapan ini penggambaran solusi dari berbagai ide yang telah didiskusikan (Ardian \& Werdhaningsih, 2019; Saputra, 2018; Yeongwon, 2018). Proses pengambaran solusi dilakukan dengan melakukan evaluasi bersama tim dengan menggabungkan kreativitas, ide dan gagasan dari tim Smartnesia Educa. Ide yang didapat oleh Smartnesia Educa adalah sebuah layanan bimbingan yang dapat menjangkau seluruh lapisan ekonomi masyarakat. Hal tersebut dilandasi oleh keadaan ekonomi masyarakat Kabupaten Bandung pada umumnya dan Desa Dayeuhkolot pada khususnya yang cukup heterogen. Ide didapat berupa beasiswa subsidi silang sehingga secara tidak langsung masyarakat ekonomi ke atas dapat membantu masyarakat ekonomi menengah ke bawah yang anaknya belajar di Smartnesia Educa. Selain faktor keuangan Smartnesia Educa menggunakan produk layanan bimbingan belajar dengan berbasis kurikulum nasional ditambah dengan penggunaan 4 pilar khas bimbingan belajar Smartnesia Educa yang terdiri dari akademik, etika, keislaman, dan entrepreneurship. Keempat pilar ini dilaksanakan secara simultan dan diintegrasikan dalam proses belajar mengajar.

Tahapan keempat yaitu prototype merupakan ide yang sudah ada sebelumnya maka perlu langsung diimplementasikan dalam sebuah produk layanan uji coba (Ardian \& Werdhaningsih, 2019; Batmetan et al., 2015; Saputra, 2018; Yeongwon, 2018). Perlu dihasilkan sebuah produk nyata dan 
kemungkinan skenario penggunaan. Memasuki tahap prototype ini mengeluarkan produk mereka sejak Agustus 2016. Prototype layanan ini merupakan wujud yang fleksibel serta belum baku untuk dijadikan sebuah dasar dan pengumpulan data dan informasi untuk pngembangan produk ke depannya. Dari hasil penelitian, tahap prototype dilakukan Smartnesia Educa dengan membuka kelas-kelas bimbingan belajar di jenjang TK, SD, SMP, dan SMA. Menggunakan kurikulum yang dibangun dengan mengacu kepada kurikulum nasional dan ditambah dengan 4 pilar khas Smartnesia Educa. Prototype produk jasa ini disempurnakan di aspek pengajaran dengan pola pengajaran yang lebih personal dan satu guru mengajar maksimal 5 siswa. Prototyping dilanjutkan pada aspek keuangan dengan subsidi silang dengan cara pembayaran dilakukan oleh siswa dari keluarga mampu dan beasiswa bimbingan belajar bagi siswa yang tidak mampu. Prototype ini diharapkan menjadi pembeda dengan bimbel lain dan menjadi keunggulan kompetitif yang dimiliki oleh Smartnesia Educa.

Tahapan kelima test merupakan tahapan uji coba produk. Produk jenis layanan belajar yang sudah dibuat oleh Smartnesia Educa akan dilakukan sebuah percobaan dengan market. Tahapan tes merupakan fase untuk memperbaiki solusi atau Prototype, dengan melakukan pengamatan serta memberi feedback untuk Prototype yang sudah dibuat agar lebih baik lagi (Batmetan et al., 2015; Yeongwon, 2018). Dari pengalaman yang didapat oleh market dalam menggunakan produk jenis layanan belajar, maka akan didapatkan masukkan untuk membuat produk yang lebih baik dan melakukan perbaikan pada produk yang ada. Hasil prototype dari Smartnesia Educa sudah di lakukan tes untuk mendapatkan feedback dari market sehingga Smartnesia Educa dapat mengembangkan produk dan layanan yang dibutuhkan oleh market.
Sejak model bisnis yang dikembangkan oleh Smartnesia Educa sesuai dengan keadaan lingkungan market, hal tersebut dapat dilihat dari bertambahnya jumlah siswa yang menggunakan layanan belajar Smartnesia Educa, bertambahnya jumlah pegawai, serta meningkatnya omset dan pendapatan. Hanya saja produk tes ini mendapat feedback berupa saran-saran perbaikan pada bidang kurikulum, jadwal, dan fasilitas. Hasil feedback ini merupakan indikator terselenggaranya proses design thinking yang dilakukan oleh Smartnesia Educa.

Berdasarkan penjelasan yang telah diuraikan sebelumnya, Smartnesia Educa telah menyelesaikan proses tahapan design thinking untuk masuk dalam usaha yang bergerak dalam bidang pendidikan dan pengembangan pasar yang diperlukan untuk mengembangkan Smartnesia Educa agar lebih besar lagi. Proses design thinking ini telah dilalui dengan baik sesuai dengan tahapannya sehingga menghasilkan produk yang benar-benar dibutuhkan oleh market (Ardian \& Werdhaningsih, 2019; Saputra, 2018), menjadikan keunggulan kompetitif bagi Smartnesia Educa, serta sesuai dengan tujuan utama Smartnesia Educa.

\section{Kesimpulan}

Smartnesia Educa telah melakukan tahapan design thinking yang dapat menjadi tools dalam menjalankan bisnisnya. Design thinking dijadikan pembuka untuk memahami kebutuhan market secara mendalam kemudian dilanjutkan dengan beragam solusi yang didapatkan dari proses design thinking (Amalina et al., 2017; Saputra, 2018). Dengan proses design thinking, maka dapat terciptalah produk layanan yang dikembangkan Smartnesia Educa yang cukup heterogen dari sisi ekonomi dan sosial, sehingga Smartnesia Educa dapat mempunyai keunggulan kompetitif dan dapat diterima oleh pasar. 


\section{Daftar Pustaka}

Ackoff, R. L., Magidson, J., \& Addison, H. J. (2006). Idealized Design. Creating an organization's future. America: Prentice-Hall. Diakses dari

http://ptgmedia.pearsoncmg.com/im ages/9780137071111/samplepages/ 0137071116.pdf

Amalina, S., Wahid, F., Satriadi, V., Farhani, F. S., \& Setiani, N. (2017). Rancang Purwarupa Aplikasi UniBook Menggunakan Metode Pendekatan Design Thinking. Seminar Nasional Aplikasi Teknologi Informasi (SNATi), 5055. Diakses dari https://journal.uii.ac.id/Snati/article/ view/8457/7185

Ambrose, G., \& Harris, P. (2010). Design Thinking: Fragestellung, Recherche, Ideenfindung, Prototyping, Auswahl, Ausführung. Feedback. Publisher: Stiebner.

Ardian, N. F., \& Werdhaningsih, H. (2019). Penggunaan Design Thinking Dalam Pengembangan Produk Kerajinan IKM (Studi Kasus: Sentra Kerajinan Patung Kayu, Subang). Jurnal Dimensi Seni Rupa dan Desain, 15(1), 1-16. doi: http://dx.doi.org/10.25105/dim.v15i $\underline{1.4193}$

Batmetan, J. R., Parera, A., Maki, K., Ondang, J., Informatika, T., \& Manado, U. N. (2018, November 11). Model Desain Thinking Pada Perancangan Aplikasi Mobile Learning. doi: https://doi.org/10.31219/osf.io/xpzy $\underline{r}$

Brown, T. (2008). Design Thinking. Harvard Business Review, 1-10. Diakses dari https://readings.design/PDF/Tim Brown, Design Thinking.pdf
Brown, T., \& Wyatt, J. (2010). Design Thinking for Social Innovation. Development Outreach, 12(1), 2943. doi: https://doi.org/10.1596/1020797X_12_1_29

Hartson, R., \& Pyla, P. S. (2012). The UX Book: Process and Guidelines for Ensuring a Quality User Experience. United States of America: Elsevier.

Ingle, B. R. (2013). Design Thinking for Entrepreneurs and Small Businesses: Putting the Power of Design to Work. New York: Apress.

Ojasalo, J. (2008). Management of innovation networks: a case study of different approaches. European Journal of Innovation Management, 11(1), 51-86. doi: https://doi.org/10.1108/1460106081 $\underline{0845222}$

Plattner, H. (2019) An Introduction to Design Thinking Process Guide. Published: Institute of Design at Stanford. Diakses dari https://dschool-

old.stanford.edu/sandbox/groups/de signresources/wiki/36873/attachme nts/74b3d/ModeGuideBOOTCAMP 2010L.pdf

Purnomo, D. (2013). Konsep Design Thinking bagi Pengembangan Rencana Program dan Pembelajaran Kreatif dalam Kurikulum Berbasis Kompetensi. Konferensi Nasional "Inovasi dan Technopreneurship" IPB International Convention Center, Bogor, 18-19 Februari 2013, 18-19.

Saputra, T. A. (2016). Implementasi Design Thinking Dalam Membangun Inovasi Model Bisnis Perusahaan Percetakan. Petra International Journal of Business Studies, 4(1), 833-844. Diakses dari 
http://publication.petra.ac.id/index.p hp/manajemenbisnis/article/view/6727

Saputra, T. A. (2018). Implementasi Design Thinking dalam Membangun Inovasi Model Bisnis Perusahaan Percetakan. Agora, 4(1), 833-844. Diakses dari http://publication.petra.ac.id/index.p $\mathrm{hp} /$ manajemenbisnis/article/view/6727/6097

Suendro, G. (2010). Analisis Pengaruh Inovasi Produk Melalui Kinerja Pemasaran untuk Mencapai Keunggulan Bersaing Berkelanjutan (Studi Kasus Pada Industri Kecil Dan Menengah Batik Pekalongan). Jurnal Sains Pemasaran Indonesia, 9(2), 230-243.
Yeongwon, L. (2018). Innovative Design Thinking Process with TRIZ. IFIP International Federation for Information Processing 2018, 541, 241-252. doi: https://doi.org/https://doi.org/10.10 07/978-3-030-02456-7_20

Zaki, A., \& Sukoco, I. (2018). Use Of Design Thinking At Digital Technology Consultant Company Indie Labtek Bandung. AdBispreneur, 3(2), 123-129. doi: https://doi.org/10.24198/adbisprene ur.v3i2.18469 